\title{
HISTORICAL MARINE POPULATION ESTIMATES: TRIGGERS OR TARGETS FOR CONSERVATION? THE DUGONG CASE STUDY
}

\author{
Helene Marsh, ${ }^{1,4}$ Glenn De’ ath,,${ }^{1,5}$ Neil Gribble, ${ }^{2}$ and Baden Lane ${ }^{3}$ \\ ${ }^{1}$ School of Tropical Environment Studies and Geography, James Cook University, Townsville, Queensland 4811, Australia, \\ and CRC Reef Research Centre Townsville, Queensland 4810, Australia \\ ${ }^{2}$ Northern Fisheries Centre, P.O. Box 5396, Cairns, Queensland 4870, Australia \\ ${ }^{3}$ Queensland Shark Control Program, Mineral House, George Street, Brisbane, Queensland 4000, Australia
}

\begin{abstract}
Recent studies have estimated the historical abundance of large marine vertebrates to determine potential targets for conservation. We evaluated this approach using 1990s aerial survey estimates of dugong abundance and an estimate of the decline in dugong numbers since the 1960s based on changes in the catch per unit effort of dugong bycatch in a government shark control program on the east coast of Queensland, Australia. This analysis indicated that the catch rate of dugongs caught in shark nets, at six locations between latitudes $16.5^{\circ} \mathrm{S}$ and $28^{\circ} \mathrm{S}$, declined at an average of $8.7 \%$ per year between 1962 and 1999. This represents a decline to $3.1 \%$ of initial catch rates over the sampling period. If the changes in the populations sampled by the shark nets and aerial surveys were equivalent, this result suggests that the region supported 72000 dugongs in the early 1960s compared with an estimated 4220 dugongs in the mid-1990s. The seagrass habitat in the region is currently insufficient to support 72000 dugongs, suggesting that our hindcast estimate may be an unrealistic target for recovery. Nonetheless, the evidence of serious dugong decline from the shark-net data and other sources has triggered significant conservation initiatives. This case study indicates that comparisons between historical and contemporary estimates of the abundance of large marine vertebrates can be powerful qualitative triggers for conservation action, but that quantitative targets for recovery require systematic testing of the assumptions underlying hindcast estimates, scientific evaluation of the current carrying capacity of the ecosystem for the target species, and consultation with a broad range of stakeholders. For some species, it may be more productive to set anthropogenic mortality targets that are designed to enable the population to recover to its optimum sustainable population than to set recovery targets per se.
\end{abstract}

Key words: conservation target; conservation trigger; dugong; estimating marine-mammal abundance; Great Barrier Reef Region; historical abundance.

\section{INTRODUCTION}

Earlier attempts to estimate the historical size of large marine mammals were often based on catch records (e.g., Mitchell and Reeves 1983, Breiwick and Mitchell 1983, Sergeant 1997, Reeves et al. 1999). More recently a wide variety of paleological, archaeological, historical, genetic, and/or catch data have been used to estimate the historical abundance of large marine vertebrates including marine mammals, sea turtles, and large predatory fish (e.g., Jackson et al. 2001, Myers and Worm 2003, Roman and Palumbi 2003). One rationale for these later studies has been to demonstrate "achievable goals for the restoration and management of coastal ecosystems" (Jackson et al. 2001: 629).

If historical estimates of abundance are to be useful targets for recovery, it is important to evaluate whether

Manuscript received 20 April 2004; revised 2 August 2004; accepted 11 August 2004. Corresponding Editor: P. K. Dayton.

${ }^{4}$ E-mail: helene.marsh@jcu.edu.au

${ }^{5}$ Present address: Australian Institute of Marine Science PMB 3, Townsville, Queensland 4810, Australia. they are achievable. There are several reasons why historical reconstructions may not produce appropriate contemporary targets: (1) long-term natural fluctuations in climate may have altered the relevant ecosystem; (2) changes resulting from anthropogenic impacts may have reduced the carrying capacity and stakeholders may not be willing (or able) to change their practices sufficiently to restore habitats to their former status, and (3) the hindcast estimates may be inaccurate. Consequently, it is important to evaluate whether targets based on hindcast estimates of abundance are realistic under contemporary conditions and to identify the reason(s) for any discrepancy.

The Great Barrier Reef World Heritage Area and the adjacent coast of southeast Queensland are some of the best-protected marine ecosystems in the world. The Great Barrier Reef Region is the world's largest marine protected area. It is located off a coast with a relatively low human population density (CIESIN 2000), and most major anthropogenic impacts are relatively recent. Large multiple-use marine parks have also been established in the two large bays on the Queensland coast 
south of the Great Barrier Reef Region, Moreton Bay and Hervey Bay. Nonetheless, as pointed out by Pandolfi et al. (2003), these regions are far from pristine, and knowledge of the historical abundance of key species is important if targets are to be developed for conservation management.

The dugong, Dugong dugon, a distant relative of the elephant, is a coastal marine mammal with a low maximum rate of increase ( $\leq 5 \% / y r$; Boyd et al. 1999). It feeds mainly on seagrasses, particularly low-biomass meadows of the tropical and subtropical genera $\mathrm{Hal}$ odule and Halophila (Marsh et al. 1982, Preen 1992, Coles et al. 2002). IUCN, the World Conservation Union, lists the dugong as vulnerable to extinction (Hilton-Taylor 2000). In most of the 37 countries and territories in the dugong's Indo-Pacific range, this evaluation is based on anecdotal information because of the difficulty in detecting trends in abundance (Marsh et al. 2002).

In Australian waters, the range of the dugong extends across the northern coast from Shark Bay in Western Australia to Moreton Bay in southern Queensland (Marsh et al. 2002). Genetic studies using MtDNA reveal two maternal lineages, which apparently reflect the effects of sea-level changes over geological time. One lineage is restricted to the coast of Queensland and part of the Northern Territory while the other occurs across the entire Australian range. Our understanding of genetic structure within this metapopulation is limited (Marsh et al. 2002). Satellite, tracking studies suggest movement heterogeneity. Some individual dugongs move hundreds of kilometers in a few days while others are sedentary (Marsh and Rathbun 1990, Marsh et al. 2002). Anecdotal and scientific information suggest that dugong numbers have declined substantially along the urban east coast of Queensland between latitudes $16.5^{\circ} \mathrm{S}$ and $28^{\circ} \mathrm{S}$ (see Marsh et al. [2002] for details). We used information collected by the Queensland Shark Control Program to hindcast changes in dugong abundance in this region since the early 1960s. We then evaluated this historical estimate as a potential target for recovery and used the dugong case study to evaluate the likely value of historical population estimates as triggers and targets for marine conservation initiatives.

\section{Methods}

\section{Change in catch per unit effort in the Queensland Shark Control Program}

Nets and drum lines have been deployed since 1962 at various popular beaches (contract beaches, where a shark-netting contractor was contracted by the state government to set shark nets for bather protection) in 10 locations (contract areas, i.e., groups of beaches for which the state government has contracted to have shark nets set by a single contractor) along the Queensland coast between Cairns $\left(16.5^{\circ} \mathrm{S}\right)$ and the Gold Coast

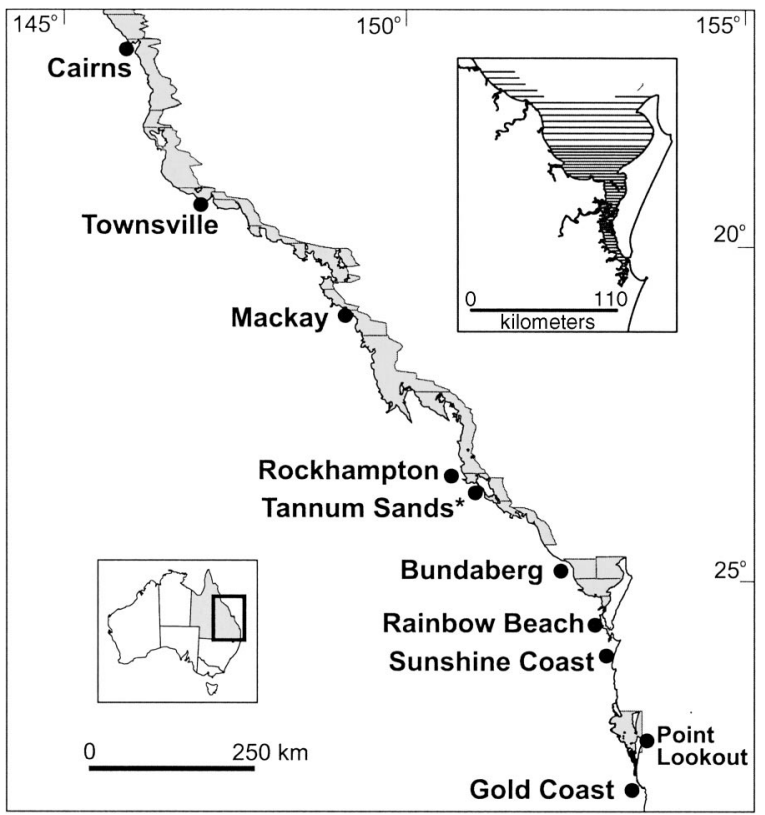

FIG. 1. Map showing the deployment of shark-control nets along the eastern coast of Queensland, Australia, and the boundaries of the aerial survey blocks. The shark nets at Point Lookout were deployed at only one beach and for seven years only (1974-1980); these data were excluded from the analyses. Moreton Bay is the bay east of Point Lookout; Hervey Bay is the bay west of Bundaberg. The top inset shows the transects in Hervey Bay as an example of the survey design used in the aerial survey blocks. No dugongs were sighted in the coastal areas that were not included in the aerial survey blocks when these areas were surveyed along transects parallel to the coast.

$\left(28^{\circ} \mathrm{S}\right)$ (Fig. 1) to reduce the numbers of resident sharks. Dugongs were caught in the nets but not by the drum lines. Data from Point Lookout where nets were deployed at a single beach for only seven years (19741980) were excluded from all our analyses. We used the following data for each month from all other beaches where shark nets were deployed: year; month; number of nets (0-3); number of days fished (effort/month); days not fished; number of months of net fishing since the nets were last removed; total number of months nets operated in area/beach; total number of dugongs caught. A total of 446 records were dropped from all analyses, reflecting inconsistencies between various versions of the government records. Thus our analysis is conservative, especially with respect to dugong mortality in the early years of the Queensland Shark Control Program; e.g., Anonymous (1992) reports a total of 837 dugongs caught between 1962 and 1992 whereas our analysis is based on a catch of 579 dugongs.

Our full data set comprised 14636 monthly records over 38 years (1962-1999) at 47 beaches. The monthly catch per beach ranged from 0 through 5 dugongs with almost $97 \%$ zero catches. These data were analyzed using log-linear models. The effects of the number of nets, the number of days fished, and the month of the 
year were assessed using analysis-of-deviance tests, based on a model including these effects together with a smooth term in year (natural spline with $4 \mathrm{df}$ ), beach, and the year $\times$ beach interaction. Thus, all effects were adjusted for all other terms in the model. As detailed in Marsh et al. (2001), the effects of the number of nets, the number of days fished, months, and net removals were statistically nonsignificant, and thus, to simplify further analyses, dugong catches were summed to give annual totals for each beach when at least one net was deployed. For years with less than 12 months of effort, totals were adjusted appropriately.

The Queensland Shark Control Program selected the 47 beaches based on the extent and pattern of human use. Hence, for catch rates of dugongs, it is reasonable to treat these beaches as representative of the relevant contract areas. On this basis, we used variation in the temporal profiles at the different beaches as the source of variation against which to compare differences between contract areas, and to obtain estimates of precision of the area and overall profiles.

The catch data were difficult to model because of: (1) the large percentage of months with zero catches, (2) the repeated measures on individual beaches, and (3) the unbalanced data resulting from the nets being deployed for different lengths of time at the various beaches. We took further steps to create a reduced data set that was more balanced and therefore more robust to statistical analysis than the full data set:

1) Data from beaches with total dugong captures $<2$ animals were removed since they provided minimal trend information.

2) Data from beaches with $<8$ years of observations were removed since, compared to the overall period of 38 years, they provided little trend information, and they also greatly increased the imbalance of the data.

3) Data from an additional contract area (Rainbow Beach) where nets were deployed at only one beach were removed since the precision of the area profile could not be estimated because of the lack of replication.

4) Data were aggregated across months to give a single total for each combination of year and beach as in the previous analysis.

This reduced data set included six of the eight contract areas (four in the Great Barrier Reef World Heritage Area), and 31 of the 47 beaches in the full data set. The number of cases was reduced from 14636 to 942 (largely because of aggregating the data from monthly to annual totals), and the total dugongs caught from 579 to 523 . The annual dugong catches for each beach were then analyzed using log-linear models. Variation of temporal profiles at the different beaches within areas was used to assess differences between areas. Bootstrapping was used to estimate mean profiles and confidence intervals for each area and overall.

\section{Hindcasting dugong abundance}

We estimated dugong numbers along this coast at the inception of the Shark Control Program by:

1) Obtaining a composite estimate of dugong numbers in the region from Cairns to the Gold Coast in the mid-1990s from standardized aerial surveys conducted in 1992, 1994-1995 and 1999 (Marsh and Saalfeld 1990, Marsh et al. 1996, Marsh and Lawler 2001, Lanyon 2003) using the method of Marsh and Sinclair (1989). The entire region was divided into blocks and each block was surveyed by flying fixed transects parallel to the coast (Fig. 1). Each aerial survey provided a snapshot estimate of dugong numbers in the relevant survey region at the time of that survey. The composite estimate was obtained by treating the various estimates of the mean number of dugongs in each survey block as random samples of dugong numbers using that block and combining them to give a composite estimate of dugong numbers using the entire region in the mid1990s.

2) Backcasting this estimate using the rate of decline estimated from the catch of dugongs per beach.

\section{Estimating whether contemporary seagrass meadows could support the hindcast dugong numbers}

We evaluated whether our hindcast estimate of dugong numbers in the region in the early 1960s could be a realistic target for recovery by considering whether the present seagrass habitat in the region could support the hindcast population. As the data are not available to estimate the dugong carrying capacity of the region directly, we used the alternative approach outlined below.

When feeding on the small, delicate species that form most of the seagrass meadows along the east coast of Queensland (Coles et al. 2003, Mellors 2004), dugongs dig up whole seagrass plants leaving feeding trails from which on average they have removed two-thirds of the above- and belowground seagrass biomass (Preen 1992). Empirical data (Preen 1992, Aragones 1996) indicate that, on average, a dugong consumes between $\sim 28$ and $40 \mathrm{~kg}$ wet mass (3.16-4.52 kg dry mass) of seagrass per day. The mean biomass of seagrass for five major dugong habitats in the Great Barrier Reef Marine Park in both the growing and senescent seasons ranged from 5.8 to $10.4 \mathrm{~g} \mathrm{dm} / \mathrm{m}^{2}$ (Coles et al. 2002); the median value for the main dugong habitat within Moreton Bay (Preen 1992) was $12.3 \mathrm{~g} \mathrm{dm} / \mathrm{m}^{2}$. Acknowledging that these estimates are approximate and that we cannot reliably estimate their precision, we used them to define a range of estimates of mean seagrass biomass for the region (5-12 $\left.\mathrm{g} \mathrm{dm} / \mathrm{m}^{2}\right)$. Dugongs spend most of their time in depths of $\leq 15 \mathrm{~m}$ (Chilvers et al. 2004). The QDPI (Queensland Department of Primary Industries) seagrass database and Abal et al. (1998) were used to define a range of estimates of the total area of seagrass in waters $\leq 15 \mathrm{~m}$ along this coast 


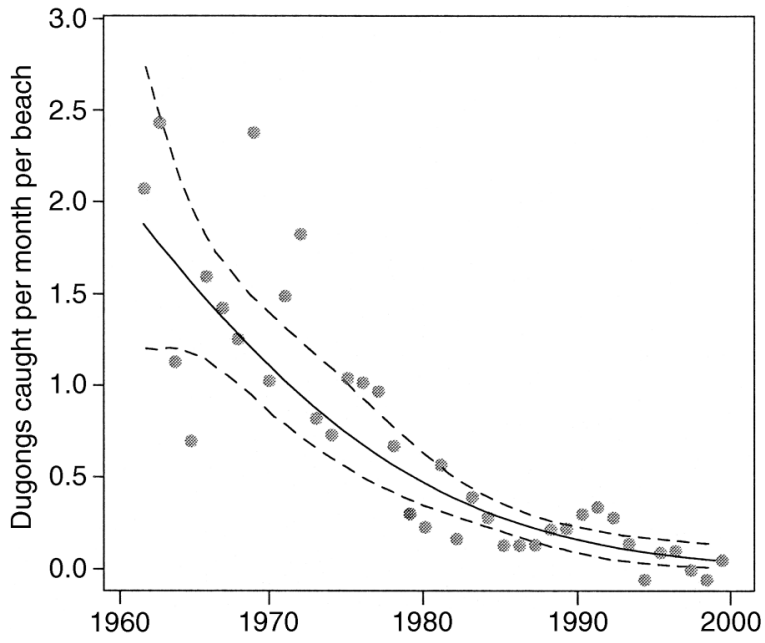

FIG. 2. Profile of the annual estimated mean numbers of dugongs caught for the period 1962-1999 for the balanced data set from six shark-netting contract areas, showing a strong overall decline in the number of dugongs caught per month per beach. The profile was estimated by bootstrapped fits of log-linear models with linear and quadratic terms in year for each beach. The bootstrap samples were generated by stratifying on beach within area; thus, for any sample, a beach was either completely included or excluded. The confidence bands have $95 \%$ pointwise coverage. The estimated rate of decline averages $8.7 \% / y r$.

(2593-3815 $\left.\mathrm{km}^{2}\right)$ including meadows of species that are not the preferred food of dugongs. We used all these data plus the mean and the bounds of the $95 \%$ CI of the hindcast estimate of dugong abundance to calculate a matrix of estimates of the number of days required for the hindcast population estimate to consume all the seagrass in the study region (Table 1 ). We then compared these estimates with contemporary data on the times taken for seagrass to recover from dugong grazing to determine the likelihood of contemporary seagrass meadows supporting our hindcast estimate of dugong abundance.

\section{RESUlts}

\section{Decline in the dugong catch per beach}

Both of our analyses of the dugong catches in the Queensland Shark Protection Program indicated that the numbers of dugongs caught declined from its inception. The estimated rate of decline for the statistically robust balanced data set from six locations (31 beaches) averaged $8.7 \%$ per year $(95 \% \mathrm{CI}=7.1,10.6)$ (Fig. 2), representing a decline of $97 \%(93.9,98.6)$ of initial catch rates over the 38-year sampling period. The overall capture rates were $8.2 \%$ per year $(6.8,9.7)$ for the full data set, only marginally lower than for the balanced data set. The catch rates varied strongly among locations (Fig. 3). Four of the six locations exhibited consistent severe declines and two showed increases followed by declines with higher catches centered on 1980-1982.

\section{Estimate of dugong numbers in the early 1960s}

Based on the aerial surveys conducted in the 1990s, the composite estimate of the number of dugongs using the region from Cairns to the Gold Coast in 1996 was 4220 individuals $(95 \%$ CI: 2360,8360$)$. The extrapolated estimate of dugong abundance in 1962 was 72000 dugongs (95\% CI: 31000,165000$)$ on the basis of the statistically robust estimate of the decline in catch per unit effort detected in the shark nets i.e., $8.7 \%$ per year (95\% cI: $7.1,10.6)$ for 34 years. The relatively large variance ( $>5$ fold) in the hindcast estimate mainly results from the relatively large variance ( 3.5 fold) of the 1996 abundance estimate based on aerial surveys compared with the estimate of the rate of decline ( 1.5 fold).

\section{Is this estimate of dugong numbers in the early 1960 s a realistic target for recovery?}

Depending on the average biomass of seagrass, we estimated that 72000 dugongs would take between 26 and 132 days to remove the entire standing stock of
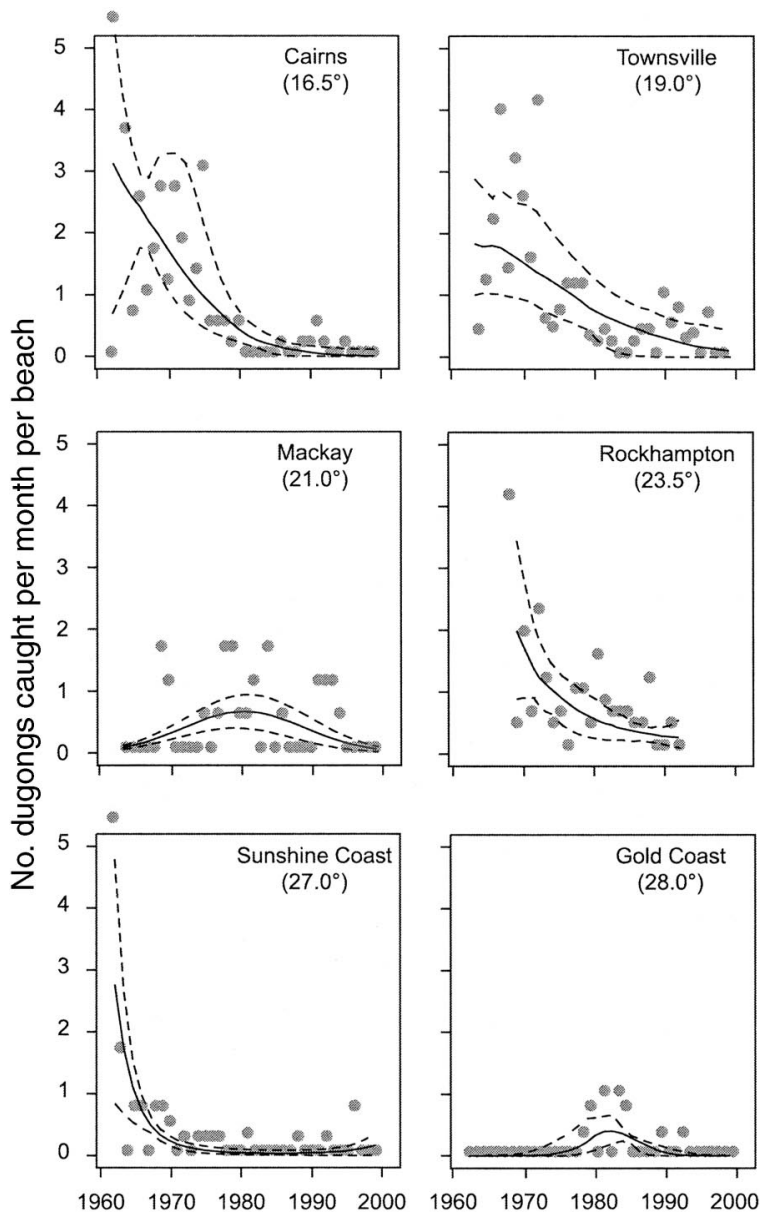

FIG. 3. Profiles of the annual estimated mean numbers of dugongs (with $95 \% \mathrm{CI}$ ) caught per beach in each of six regions along the eastern coast of Queensland for the period 19621999. Out-of-range points for Cairns and the Sunshine Coast had values of 6.5 and 6 dugongs, respectively. 
TABLE 1. Estimated number of days that the hindcast estimate of dugong abundance $\left(31-165 \times 10^{3}\right.$ individuals $)$ in 1962 would take to completely dig up once all the seagrass in the coastal waters of Queensland (Australia) between $16.5^{\circ} \mathrm{S}$ and $28^{\circ} \mathrm{S}$ (total area $\leq 15 \mathrm{~m}$ deep. $2593-3815 \mathrm{~km}^{2}$ ).

\begin{tabular}{|c|c|c|c|c|c|c|c|c|c|}
\hline \multirow{3}{*}{$\begin{array}{c}\text { Average } \\
\text { seagrass } \\
\text { biomass } \\
\left(\mathrm{g} \mathrm{dm} / \mathrm{m}^{2}\right) \dagger\end{array}$} & \multirow[b]{3}{*}{$\begin{array}{c}\text { Dugong } \\
\text { abundance } \$\end{array}$} & \multicolumn{4}{|c|}{ Each dugong eats $28 \mathrm{~kg}$ wet mass $/ \mathrm{d}$} & \multicolumn{4}{|c|}{ Each dugong eats $40 \mathrm{~kg}$ wet mass/d } \\
\hline & & \multirow{2}{*}{$\begin{array}{c}\text { Area } \\
\text { disturbed } \\
\text { per day } \\
\left(\mathrm{km}^{2}\right)\end{array}$} & \multicolumn{3}{|c|}{$\begin{array}{l}\text { No. days to disturb entire area } \\
\text { of seagrass once }\end{array}$} & \multirow{2}{*}{$\begin{array}{c}\text { Area } \\
\text { disturbed } \\
\text { per day } \\
\left(\mathrm{km}^{2}\right)\end{array}$} & \multicolumn{3}{|c|}{$\begin{array}{l}\text { No. days to disturb entire area } \\
\text { of seagrass once }\end{array}$} \\
\hline & & & $2593 \mathrm{~km}^{2}$ & $3204 \mathrm{~km}^{2}$ & $3815 \mathrm{~km}^{2}$ & & $2593 \mathrm{~km}^{2}$ & $3204 \mathrm{~km}^{2}$ & $3815 \mathrm{~km}^{2}$ \\
\hline 5 & $\begin{array}{r}31000 \\
72000 \\
165000\end{array}$ & $\begin{array}{r}30 \\
70 \\
160\end{array}$ & $\begin{array}{l}86 \\
37 \\
16\end{array}$ & $\begin{array}{r}107 \\
46 \\
20\end{array}$ & $\begin{array}{r}127 \\
55 \\
24\end{array}$ & $\begin{array}{r}43 \\
100 \\
229\end{array}$ & $\begin{array}{l}61 \\
26 \\
11\end{array}$ & $\begin{array}{l}75 \\
32 \\
14\end{array}$ & $\begin{array}{l}89 \\
38 \\
17\end{array}$ \\
\hline 9 & $\begin{array}{r}31000 \\
72000 \\
165000\end{array}$ & $\begin{array}{l}18 \\
41 \\
94\end{array}$ & $\begin{array}{r}144 \\
63 \\
28\end{array}$ & $\begin{array}{r}178 \\
78 \\
34\end{array}$ & $\begin{array}{r}212 \\
93 \\
41\end{array}$ & $\begin{array}{r}25 \\
59 \\
135\end{array}$ & $\begin{array}{r}101 \\
44 \\
19\end{array}$ & $\begin{array}{r}125 \\
55 \\
24\end{array}$ & $\begin{array}{r}148 \\
65 \\
28\end{array}$ \\
\hline 12 & $\begin{array}{r}31000 \\
72000 \\
165000\end{array}$ & $\begin{array}{l}13 \\
29 \\
67\end{array}$ & $\begin{array}{r}203 \\
89 \\
39\end{array}$ & $\begin{array}{r}251 \\
110 \\
48\end{array}$ & $\begin{array}{r}299 \\
132 \\
57\end{array}$ & $\begin{array}{l}18 \\
42 \\
95\end{array}$ & $\begin{array}{r}142 \\
63 \\
27\end{array}$ & $\begin{array}{r}176 \\
77 \\
33\end{array}$ & $\begin{array}{r}209 \\
92 \\
40\end{array}$ \\
\hline
\end{tabular}

Notes: Comparison with contemporary estimates of the time taken by seagrass in the study region to recover from dugong grazing indicates that it is unlikely that contemporary seagrass resources could support the hindcast estimate of dugong abundance unless the number of dugongs present was close to the lower bound of the $95 \%$ confidence interval. Empirical data on dugong consumption are from Preen (1992) and Aragones (1996).

$\dagger$ Seagrass data are from surveys conducted by Queensland Department of Primary Industries for the Great Barrier Reef region and Hervey Bay, and by Preen (1992) and Abal et al. (1998) for Moreton Bay, as explained in text (see Methods: Estimating whether contemporary seagrass meadows could support the windcast dugong number).

$\$$ The number entries are the mean (72 000) and upper (165000) and lower (31000) bounds of the 95\% confidence intervals of the hindcast estimates of dugong abundance.

seagrass in the region, assuming none of it was dug up again by dugongs during the recovery process (Table 1 ). The corresponding values for 31000 dugongs (lower bound of $95 \% \mathrm{CI}$ ) are 61 to 299 days; for 16500 dugongs (upper bound of $95 \% \mathrm{CI}$ ), 11 to 57 days. Experimental field trials of natural and simulated dugong feeding trails in this region indicate that the recovery time of seagrasses from grazing disturbances by dugongs depends on the location of the seagrass bed, the timing and the intensity of the grazing, the species composition and location within the beds (which are generally confounded), and the occurrence of additional disturbance from dugongs or other sources during recovery (Aragones and Marsh 2000). Recovery times are $<30$ to 200 days (exceptionally clear water in eastern Moreton Bay $\sim 27^{\circ} \mathrm{S}$, Preen 1995; Kathryn McMahon, personal communication [2004]) or several months to a year (turbid water more typical of the region at Cardwell $\sim 18^{\circ} \mathrm{S}$, Aragones and Marsh 2000). We conclude that there is not enough seagrass in the region today to support our hindcast estimate of dugong abundance unless the true population size was close to the lower bound of the $95 \% \mathrm{CI}$, especially as the seagrass in the region is not all equally attractive and available to dugongs as assumed in our analysis.

\section{DISCUSSION}

Our hindcast estimate of dugong numbers should not be used as a target for recovery of dugongs along the Queensland (Australia) coast between Cairns $\left(16.5^{\circ} \mathrm{S}\right)$ and the Gold Coast $\left(28^{\circ} \mathrm{S}\right)$. It is both imprecise and too high to be achievable under contemporary conditions. The 40-year time frame over which the shark meshing records were collected means that long-term natural changes in the seagrass ecosystem are an unlikely explanation for this result. This leaves two alternative hypotheses that are not mutually exclusive: (1) our hindcasting is upwardly biased as well as imprecise, and (2) anthropogenic impacts have reduced the region's carrying capacity for dugongs.

\section{Is our hindcast estimate upwardly biased?}

If our hindcasting is biased, a likely reason is that one or more of the underlying assumptions is incorrect. We evaluate these assumptions below.

Assumption 1: decline in the dugong catch per unit effort (CPUE) is a reliable index of the decline in $d u$ gong numbers averaged over the areas where nets were deployed (the unit of effort was the annual dugong catch per beach).-We examine three assumptions further underlying this approach below.

1. Practices of shark netting did not change over the sampling period.-The Queensland Shark Control Program has used the same type of nets since its inception (Anonymous 1992). These nets were initially bottom set, but have been set from the surface in a standardized manner since the first few months of the program. In 1992 the Queensland Shark Control Program introduced measures to reduce the capture of nontarget species as detailed in Gribble et al. (1998). These measures included: the replacement of shark nets at Rockhampton and at one beach near Townsville with drum lines, education and training for contractors to increase the chances of nontarget species being released alive, and the staged introduction of acoustic alarms on nets at beaches in the Gold Coast (from 
1992-1993), Sunshine Coast (from 1994 whales, 1998 dolphins), and Cairns contract areas (from 1994-1995). These alarms were introduced to reduce the probability of accidental entanglement of cetaceans. The behavior of wild dugongs was not altered by similar alarms in experimental trials (Amanda Hodgson, personal communication [2003]). We conclude that the changes in the practice of shark meshing are unlikely to have had a major impact on the long-term declines in dugong catch (Fig. 2), especially as they were not implemented until the 1990s.

2. Dugongs did not change their behavior in the areas fished by the shark nets.-The nets were left in place at each location for long periods. We have no data to support the assumption that dugongs did not change their behavior in response to the nets and limited data to test the hypothesis that dugongs learned to avoid the nets. Most captures were of single dugongs and the only long-term social unit identified for dugongs is the cow-calf pair, suggesting limited opportunity for dugongs to learn about the nets from the experience of others. The confirmed proportion of animals released alive from the nets is low (2\%, Anonymous 1992). However, this percentage probably underestimates the actual percentage released alive as the status of most dugongs in the nets was not recorded. We have no data on how many dugongs escaped from the nets unassisted.

Dugongs of all ages and both sexes were caught, and the distributions of sizes, sexes, and estimated ages contained no major gaps (Marsh 1980). If dugongs learned to avoid nets we might expect a preponderance of young animals in the nets and a rise in dugong catch rates when the nets were reintroduced each year after their annual maintenance removal. This did not occur (Marsh et al. 2001); however, the removal time may have been too short for dugongs to unlearn any avoidance behavior. We conclude that net avoidance cannot explain the decline in dugong catches.

Another possible explanation for the decline in $\mathrm{du}$ gong by-catch is that dugongs were displaced from the beaches where shark nets have been located by increased human use between 1962 and 1999. Although boat traffic is banned from the immediate vicinity of nets, the presence of a net was presumably an inducement to bathers to increase their use of the area. There is no evidence to reject or support this displacement hypothesis.

3. Catch rates were dependent on dugong density.Analysis of the dugong by-catch by contract area (Fig. 3) indicates strong declines between the early $1960 \mathrm{~s}$ and 1999 in four of the six areas: Cairns, Townsville, Rockhampton (all in Great Barrier Reef World Heritage Area), and the Sunshine Coast (Fig. 1). The catch rates in Fig. 3 suggest that the number of dugongs remaining in the contract areas should be higher in Townsville and Rockhampton than in Cairns, and variable in Mackay. These patterns are broadly consistent with the pat- terns of dugong abundance indicated by the dedicated aerial surveys for dugongs conducted in 1986-1987, 1992, 1994, and 1999 (Marsh and Saalfeld 1990, Marsh et al. 1996, Marsh and Lawler 2001).

Two of the shark-meshing contract areas (Mackay and the Gold Coast, Fig. 1) showed a modal distribution of catches, with higher catches centered on 1980-1982. This pattern also accords with the hypothesis of changes in seagrass and hence dugong distribution in response to extreme weather events (Heinsohn and Spain 1974, Preen and Marsh 1995, Marsh and Lawler 2001, 2002, Gales et al. 2004, Marsh et al. 2004). We hypothesize that dugongs moved into the Mackay and Gold Coast contract areas in response to seagrass loss elsewhere (see Marsh et al. 1999).

We conclude that the decline in dugong catches illustrated in Fig. 2 reflects a major decline in the number of dugongs at least in the local areas fished by the nets. This large decline is confirmed by both anecdotal and scientific information. Aboriginal elders consider that dugong numbers in the southern Great Barrier Reef World Heritage Area have been declining for decades. The large decline in the Cairns region (Fig. 3) is supported by both (1) the aerial survey results (too few dugongs were seen in the region to estimate dugong abundance in 1987, 1993, and 1999), and (2) Bertram and Bertram's (1973) report that 200 dugongs per year were being taken by Aboriginal people from a nearby community in 1965 . The temporal changes in dugong numbers in the study region monitored by aerial surveys since the mid-1980s (Marsh et al. 1996, Marsh and Lawler 2001) reflect migration between the survey region and adjacent areas as well as changes in the overall size of the Australian dugong metapopulation, emphasizing the need to use historical data as well as contemporary monitoring to evaluate the status of longlived and mobile animals such as dugongs.

Assumption 2: the decline in dugong abundance averaged over the areas where nets were deployed is a reliable index of the change in the dugong abundance in the whole region sampled by the aerial surveys.The aerial surveys sampled dugongs off the east coast of Queensland between Cairns and the Gold Coast, a region spanning the locations where the shark nets were deployed. Unfortunately, we do not know if the dugong population in this region is structured or panmictic. However, there is evidence from both the shark netting and the aerial surveys that the temporal changes in dugong abundance are not uniform throughout the region. For example, the catch rates in the shark nets varied strongly among locations (Fig. 3) as discussed above.

In addition, dugong numbers appear to have recovered during the 20th century in Moreton Bay near Brisbane, site of a commercial fishery for dugongs between 1846 and 1920 (Johnson 2002), despite its proximity to the rapidly growing city of Brisbane. The overall trend in dugong numbers reflected by aerial surveys in 
Moreton Bay since the 1970s indicates that dugong numbers have been stable or increasing during this period (Lanyon et al. 2003). In contrast, analysis of the data from the aerial surveys for the region as a whole in the 1990s suggests an overall weak decline in the dugong population between the mid-1980s and mid1990 s, a pattern that is not inconsistent with the rate of decline estimated from the shark nets (H. Marsh, unpublished data).

We conclude that the decline in dugong catches illustrated in Fig. 2 reflects the situation in the local areas fished by the nets, but we are less confident that the decline is consistent over the region as whole. Since we cannot identify the boundaries of the regions fished by the nets, we cannot adjust the contemporary estimates of dugong abundance to improve our hindcast estimates.

Assumption 3: the estimates of dugong abundance from the aerial surveys are unbiased.-The capacity of aerial surveys to provide reasonably unbiased snapshots of dugong abundance has recently been verified experimentally by Pollock et al. (in press). This leads to greater confidence that the fluctuations in dugong abundance indicated by the 1992, 1994-1995 and 1999 aerial surveys reflect movements within the dugong metapopulation rather than survey inadequacies. Gales et al. (2004) and Marsh et al. (2004) conclude that dugongs undertake large-scale movements at spatial scales larger than that considered in this study, principally in response to seagrass dieback events. These movements are the main cause of the relatively large variance of our composite estimate of dugong abundance in the mid-1990s and the relatively large variance in our hindcast estimate.

\section{Could anthropogenic impacts have reduced the region's carrying capacity for dugongs?}

A reduction in the carrying capacity of the region for dugongs is another possible explanation of why our mean hindcast estimate appears implausibly high. Abal et al. (1998) estimated that $20 \%$ of the seagrass habitat in Moreton Bay has been lost since European settlement in the 1820 s because of increased turbidity resulting from agricultural and coastal development. However, as pointed out by Coles et al. (2003), the likely effect of such anthropogenic changes is more difficult to estimate in the Great Barrier Reef Region where turbidity is naturally high in inshore waters. Most seagrasses losses in northeastern Australia in recent years have been associated with extreme weather events (Preen et al. 1995, Poiner and Peterkin 1996) and have been followed by significant recovery after several years (Coles et al. 2003).

The significant declines in the populations of dugongs and green turtles may have allowed seagrass communities dominated by Zostera capricorni to develop in some areas (Preen 1995), resulting in an overall increase in seagrass biomass (Coles et al. 2003).
However this may have resulted in an overall reduction of high-quality dugong habitat because Halodule and Halophila are favored by dugongs (Marsh et al. 1982). These genera comprise pioneer species, and experiments show that excluding dugongs results in a change in community composition with a resultant reduction in the quality of the dugong's diet (Preen 1995, Aragones and Marsh 2000).

Chronic herbicide exposure from agricultural runoff in the region may also have reduced seagrass productivity (Haynes et al. $2000 a, b$ ). Conversely, although some seagrass may have been lost through bottom trawling, it is also possible that bottom trawling may have stimulated the recovery of Halophila and Halodule through disturbance of the seed bank (Jane Mellors, personal communication [2003]).

We conclude that changes in biomass, areal extent, community composition, or productivity of the dugong habitat on the east coast of Queensland since the $1960 \mathrm{~s}$ cannot be quantified. Thus we cannot accept or reject habitat loss as the reason why the region could not currently support the a dugong population as large as our hindcast estimate.

\section{Alternative targets for recovery?}

Our conclusion that our mean hindcast estimate is not a realistic recovery target for dugongs along the urban Queensland coast suggests that the much higher estimates of dugong numbers along the entire east coast of Queensland from the tip of Cape York south in the late 19 th century $\left(1-3.6 \times 10^{6}\right.$ individuals $)$ presented by Jackson et al. (2001) are extreme overestimates. These numbers were extrapolated from anecdotal estimates of the area occupied by two large herds (one in Wide Bay in the 1870s, Thorne 1876; the other in Moreton Bay in 1893, Welsby 1905), multiplied by a measure of the density of animals within a herd based on a single published aerial photograph of 28 dugongs (which were clumped presumably in response to the circling aircraft) and an assumption that 10 large bays on the east coast of Queensland each supported similar numbers of dugongs.

We clearly cannot estimate a realistic quantitative target for dugong recovery on the urban coast of Queensland on the basis of current historical population estimates. Nonetheless, conservation initiatives to reduce dugong mortality and protect dugong habitats have been triggered by the historical evidence of dugong decline as outlined below.

\section{Historical records of dugong decline as a trigger for conservation actions}

Historical reports from the late 19th century (Thorne 1876, Welsby 1905) of dugong herds that were much larger than those recorded in the 20th century suggest that dugong numbers declined between European settlement and 1960. A cottage commercial industry for dugong oil was conducted intermittently at several lo- 
cations along the Queensland coast from the latter half of the 19th century until dugongs were protected in 1967 (Nishiwaki and Marsh 1985, Johnson 2002). In addition, in 1922 the naturalist Banfield (see Bowen and Bowen 2003) documented dugongs being killed by the crews of Japanese pearling luggers in the Great Barrier Reef Region. Both these activities probably contributed to the decline of dugongs in the coastal waters off the east coast of Queensland between European settlement and the commencement of the Queensland Shark Protection Program. The decline we have documented in the catch per unit effort in the shark nets (Fig. 2) and the anecdotal reports of local traditional owners of this sea country indicate further serious decline since the 1960s.

The relative importance of the various causes of the long-term decline in dugong numbers along the urban coast of Queensland cannot be quantified and probably varies in both space and time (Marsh et al. 1996). The likely causes include the commercial dugong industry, traditional hunting, poaching, incidental drowning in commercial gill nets as well as the shark nets set for bather protection, vessel strike, and habitat loss (Marsh et al. 1996). Triggered by the overall evidence of dugong decline and more generic conservation concerns, the relevant management agencies are attempting to address all known human impacts on dugongs as follows:

1) The commercial dugong industry has been banned since the 1960s.

2) The Great Barrier Reef Marine Park Authority no longer issues permits for traditional hunting along the urban coast of the Great Barrier Reef World Heritage Area, including our entire study region. However, it is recognized that limits to traditional hunting are difficult to implement because of native title rights. The Australian Minister of Environment has instructed that this matter be addressed with high priority and management agency staff are working with traditional owners to develop a mutually acceptable, legal framework for sustainable dugong hunting throughout Queensland.

3) Drum lines have replaced shark nets at most locations after reviews of the Shark Control Program (Anonymous 1992).

4) Commercial netting has been greatly restricted or banned from $2407 \mathrm{~km}^{2}$ of Dugong Protection Areas A and subject to lesser restrictions in $2243 \mathrm{~km} \mathrm{~km}^{2}$ of Dugong Protection Areas B in the Great Barrier Reef Region. In addition, netting practices have been modified in a $1703-\mathrm{km}^{2}$ Dugong Protection Area in Hervey Bay (Marsh 2000). Enforcement has been increased to police these regulations.

5) The Representative Areas Program increased the percentage of the $344400 \mathrm{~km}^{2}$ Great Barrier Reef Marine Park, zoned as "no-take," to $33 \%$ from mid-2004, increasing the protection afforded to dugongs and seagrass beds from fishing impacts. ${ }^{6}$

${ }^{6}\langle$ http://www.reefed.edu.au/rap/ $\rangle$
6) The Australian military has banned the use of high explosives in some parts of the Great Barrier Reef World Heritage Area to protect marine mammals.

7) Voluntary vessel lanes and/or speed restrictions have been introduced to protect dugongs from vessel strikes in several major dugong habitats (Marsh et al. 2002).

8) Dugongs receive some protection from the marine parks in Hervey Bay and Moreton Bay to the south of the Great Barrier Reef Marine Park (Marsh et al. 2002).

9) The threat to dugong habitats on the urban coast of Queensland from terrestrial run-off (Schaffelke et al. 2001) is being addressed by the Commonwealth and Queensland Governments, which have agreed through a Memorandum of Understanding to jointly develop and implement a Reef Water Quality Protection Plan to protect the region from these land-based sources of pollution (available online). ${ }^{7}$ This initiative includes a proposal to review the use of the herbicide diuron, which has been detected in both dugong tissues and the sediments associated with seagrass beds (Haynes et al. $2000 a, b)$ and that reduced the photosynthetic performance of Halodule ovalis and Zostera capricorni in laboratory experiments.

10) Standards have been introduced for sewage outfalls and the treatment of sewage on island resorts in the Great Barrier Reef World Heritage Area. Sewage treatment has also been upgraded in Moreton Bay.

11) Dugong mortality is monitored through a carcass salvage program (e.g., Haines and Limpus 2001).

12) A dugong research strategy has been developed and implemented (Oliver and Berkelmans 1999).

Determining how these initiatives might individually and collectively contribute to measurable changes in trends in dugong abundance is virtually impossible for several reasons including: (1) the lack of understanding of the spatial boundaries to dugong populations, (2) the lack of quantitative understanding of the relative importance of and spatial variation in the historical causes of dugong decline, (3) the fact that the initiatives described above have been implemented using the "precautionary principle" rather than as part of a controlled experiment in adaptive management sensu Walters (1997), and (4) the difficulty in detecting trends in dugong numbers.

After the initial aerial surveys for dugongs, power analysis using the approach of Gerrodette (1987) was used to guide the spatial scale and timing of the aerialsurvey schedule. Marsh and Saalfeld (1989) and Marsh (1995) concluded that it was more cost effective to monitor dugongs over very large spatial scales ( $\sim 30000 \mathrm{~km}^{2}$, which support thousands of animals) every five years than over smaller spatial scales more often. However, because dugongs move more than anticipated, the spatial scales over which the surveys have been conducted are now considered inadequate because

\footnotetext{
${ }^{7}\langle$ http://www.deh.gov.au/coasts/pollution/reef/index.html〉
} 
the large-scale movements of animals between surveys transcend the boundaries of even these very large survey areas (Marsh and Lawler 2001, 2002, Gales et al. 2004, Marsh et al. 2004). This is why we used a composite estimate of the number of dugongs using the region from Cairns to the Gold Coast as the baseline for our hindcasting. This composite estimate has a much higher standard error (34\%) than the estimates based on individual surveys of the region (13-16\%). Using the composite estimate and the approach of Gerrodette (1987), we estimate that at least 16 annual surveys would be required to demonstrate with high power that a dugong population increasing at $5 \%$ per year was actually increasing (5\% per year is the highest increase that is likely to be achievable given the dugong's demographics; Boyd et al. 1999). If the surveys were further apart, the time frame would be longer, although the overall cost of the surveys would be less. If we use a coefficient of variation more typical of the population estimates obtained from single surveys (15\%), at least 10 annual surveys would be required. These time frames are too long for managers under political pressure to evaluate whether their management initiatives are working. In addition as discussed above, this approach (using the precautionary principle) will not allow managers to determine which of their initiatives is making the greatest contribution to recovery without additional information. In addition, recovery is likely to be confounded with dugong movements and changes in dugong life-history parameters caused by seagrass loss and recovery over time frames that are shorter than those required to measure population recovery (see Preen and Marsh 1995, Kwan 2002).

\section{A target for recovery?}

The duty of the Great Barrier Reef Marine Park Authority is to protect the dugong as one of the outstanding natural values of the Great Barrier Reef World Heritage Area (GBRMPA 1981). However, no one has defined what this means. In 1998, the Australian National Audit Office (ANAO 1998:4) criticized the Great Barrier Reef Marine Park Authority for not having adequate data to determine whether it is achieving "its primary objective of protecting, conserving and allowing for reasonable use of the Great Barrier Reef Marine Park." In a follow-up report (ANAO 2003), the Audit Office noted that the required performance information was being developed. This has not yet been done for dugongs.

A target for dugong recovery based only on an extrapolated historical estimate of abundance would be simplistic. Rather than develop recovery targets based on population size against which it will be very difficult to monitor performance because of the difficulties in estimating trends in population size discussed above, it may by more productive to set targets for sustainable levels of anthropogenic mortality using the potential biological removal (PBR) method (Wade 1998). The
"PBR" is defined as the maximum number of animals, not including natural mortalities, that may be removed from a marine mammal stock while allowing that stock to reach or maintain its optimum sustainable population, which is defined as a population level between carrying capacity and the population size at maximum net productivity. Thus the specific goal of the PBR is to allow each stock to reach or maintain a level at or above the maximum net productivity level (MNPL; Wade 1998). The PBR is calculated using the following formula (Wade 1998):

$$
\mathrm{PBR}=N_{\min } \times 0.5 R_{\max } \times \mathrm{RF} .
$$

The minimum population estimate of the stock $N_{\text {min }}$ is defined as the 20th percentile of a log-normal distribution based on an absolute estimate of the number of animals $N$ in that stock. Our composite estimate of dugong abundance between Cairns and the Gold Coast produces an $N_{\min }$ of 3203 .

$R_{\max }$ is the maximum rate of increase and $0.5 R_{\max }$ is a conservative surrogate for $R_{\mathrm{MNPL}}$ because $0.5 R_{\max }$ will always be $<R_{\text {MNPL }}$ if MNPL is $\geq$ carrying capacity (Wade 1998). The estimates of $R_{\max }$ are based on empirical estimates of age of first reproduction and fecundity obtained by Boyd et al. (1999) and Kwan (2002) and a pattern of natural mortality based on that obtained from longitudinal studies of manatees (Eberhardt and O'Shea 1995, Langtimm et al. 1998). In view of the uncertainty associated with these estimates, we used a range of estimates for $R_{\max }$ of 0.01 to 0.05 (1$5 \%$ ).

A recovery factor $(\mathrm{RF})$ of $<1$ allocates a proportion of expected net production towards population growth and compensates for uncertainties that might prevent population recovery, such as biases in the estimation of $N_{\min }$ and $R_{\max }$, or errors in the determination of stock structure. Given that the Great Barrier Reef Region is a World Heritage Area and that the dugong is explicitly listed as a World Heritage Value (GBRMPA 1981), some stakeholders will argue for a very conservative recovery factor of 0.1 . Others may argue for the default value of 0.5. We have used both (Table 2).

The resultant estimates of the PBR for the region from Cairns to the Gold Coast range from 2 to 40 (Table 2 ). These estimates suggest that for a precautionary recovery factor of 0.1 , management should be implemented with the aim of achieving an anthropogenic mortality target of zero. Progress in achieving this target could be monitored through the carcass-salvage program (e.g., Haines and Limpus 2001), acknowledging that (1) this program will inevitably fail to recover an unknown proportion of carcasses, (2) an unknown proportion of carcasses will result from natural mortalities, and (3) the cause of death of a significant fraction will be unable to be determined. Admitting these inadequacies, a second advantage of this approach is that the necropsy program potentially allows managers to evaluate their initiatives by tracking the relative im- 
TABLE 2. Estimated mortality targets for dugongs along the urban coast of Queensland, Australia, for five levels of the maximum rate of increase $\left(R_{\max }\right)$ and two levels of the recovery factor (RF) sensu Wade (1998).

\begin{tabular}{cccccc}
\hline \hline & \multicolumn{5}{c}{$R_{\max }$} \\
\cline { 2 - 6 } RF & 0.01 & 0.02 & 0.03 & 0.04 & 0.05 \\
\hline 0.1 & 2 & 3 & 5 & 6 & 8 \\
0.5 & 8 & 16 & 24 & 32 & 40 \\
\hline
\end{tabular}

Notes: The estimates are based on the maximum number of animals, not including natural mortalities, that could be removed from the population while allowing it to reach or maintain its optimum sustainable level, which is defined as a population level between carrying capacity and the population size at maximum net productivity (Wade 1998). The estimates indicate that for a precautionary recovery factor of 0.1 , the anthropogenic mortality target should be zero. See Discussion: A target for recovery? for further explanation.

portance of the various sources of mortality (assuming that the resultant carcasses are equally available). Using this approach the major justification for aerial surveys at regular intervals (say every five years) would be to update the sustainable anthropogenic mortality target using the PBR technique (Wade 1998).

We suggest that the relevant managing agencies should use this approach to negotiate an agreed-upon anthropogenic mortality target for dugongs in the region, in consultation with all relevant stakeholders, especially the traditional owners of the region for whom the dugong has high cultural value (Marsh 1996) and who potentially have shared title over their sea country.

\section{Conclusions}

This case study demonstrates that comparisons between contemporary and historical estimates of the abundance of large marine vertebrates can be powerful qualitative triggers for conservation action. Such comparisons also have the potential to inform the development of targets for recovery. However, historical estimates should not be used as quantitative targets for recovery without (1) making the assumptions underlying these estimates explicit and systematically testing them, (2) research to estimate current carrying capacity and pressures on the relevant species and their habitats, and (3) consultation with a broad range of stakeholders about removing these pressures. As pointed out by Agardy et al. (2003), the enthusiastic prescription of simplistic targets for solving marine conservation problems risks polarizing competing interests and may ultimately stymie progress. Targets that allow us to balance human well-being and biodiversity conservation are required.

Various authors including Dayton et al. (1998) and Roman and Palumbi (2003) have commented on the difficulties associated with developing appropriate conservation and restoration goals for marine ecosystems and species. The assessment of whether management actions are achieving their goals requires the capacity to measure the effectiveness or otherwise of manage- ment actions against agreed-upon and realistic targets. Whether these targets are population size targets or sustainable anthropogenic mortality targets will depend on the demography of the species concerned and the logistics and cost of measuring population size and human-induced mortality.

We suggest that such targets should be developed as part of programs of adaptive environmental assessment and management, which are structured processes of "learning by doing" (Walters 1997). A range of targets over appropriate time frames could be developed through dynamic models that attempt to make predictions about the effects of alternative management scenarios, which could be negotiated with stakeholders and applied as large-scale management experiments.

In the case of the $344400-\mathrm{km}^{2}$ Great Barrier Reef Marine Park, the Representative Areas Program (see footnote 6) provides an unparalleled opportunity for such a large-scale management experiment. As of July 2004 , the percentage of each of the 70 bioregions zoned as "no-take" has been increased at least 20\%. These no-take areas are large, with an average size of 700 $\mathrm{km}^{2}$, and replicated within bioregions. The demand for recovery targets for high-profile species, especially commercially important reef fish, is likely to be strident. All stakeholders, especially fishers and conservationists, are keen for the effects of the rezoning of $33 \%$ of the Great Barrier Reef Marine Park as no-take to be quantified. They want to know whether this rezoning is sufficient for the Great Barrier Reef Marine Park Authority to achieve its mandate. As the preferred targets of various stakeholder groups will be influenced by their values, it would be prudent for the Authority to develop the process outlined above to negotiate agreed-upon population or mortality targets for key species as soon as possible, and to institute the monitoring required to evaluate whether these targets are being met.

\section{ACKNOWLEDGMENTS}

The Great Barrier Reef Marine Park Authority funded this project. Carole Eros examined the QDPI records and obtained detailed effort data from the Manager of the Queensland Shark Control Program (Baden Lane). Helen Penrose and Alexa Kershaw completed the arduous task of entering all blank records (months fished without dugong catches). Len McKenzie kindly supplied records of seagrass in the Great Barrier Reef Region and Hervey Bay from the Queensland Department of Primaries Industries (QDPI) seagrass database. We also thank Jeremy Jackson and Terry Hughes for robust discussions on the likely sizes of historical populations of large marine vertebrates and Richard Kenchington, Britta Schaffelke, Kirstin Dobbs, Kathryn McMahon, Jane Mellors, Paul Dayton, and two anonymous reviewers for constructive comments on various versions of the draft manuscript.

\section{Literature Cited}

Abal, E. G., W. G. C. Dennison, and M. H. O'Donohue. 1998. Seagrasses and mangroves in Moreton Bay. Pages 269-278 in I. R. Tibbetts, N. J. Hall, and W. C. Dennison, editors. Moreton Bay and catchment. University of Queensland, Brisbane, Queensland, Australia. 
Agardy, A., P. Bridgewater, M. P. Crosby, P. K. Dayton, R. Kenchington, D. Laffoley, P. McConney, P. A. Murray, J. E. Parks, and L. Peau. 2003. Dangerous targets? Unresolved issues and ideological clashes around marine protected areas. Aquatic Conservation: Marine and Freshwater Ecosystems 13:353-367.

ANAO [Australian National Audit Office]. 1998. Commonwealth Management of the Great Barrier Reef. Number 33 1997/98. Australian Government Publishing Service, Canberra, Australian Capital Territory, Australia.

ANAO. 2003. Commonwealth Management of the Great Barrier Reef: Follow Up Audit Australian National Audit Office. Report Number 8 2003-04. Australian Government Publishing Service, Canberra, Australian Capital Territory, Australia.

Anonymous. 1992. Review of the operation and maintenance of shark meshing equipment in Queensland waters. Report of the Committee of Enquiry. Queensland Department of Primary Industries, Brisbane, Queensland, Australia.

Aragones, L. 1996. Dugongs and green turtles: grazers in the tropical seagrass ecosystem. Dissertation. James Cook University, Townsville, Queensland, Australia.

Aragones, L., and H. Marsh. 2000. Impact of dugong grazing and turtle cropping on Tropical seagrass communities. Pacific Conservation Biology 5:277-288.

Bertram, G. C. L., and C. K. Bertram. 1973. The modern Sirenia their distribution and status. Biological Journal of the Linnean Society (London) 5:297-338.

Bowen, J., and M. Bowen. 2003. The Great Barrier Reef. History, science, heritage. Cambridge University Press, Cambridge, UK

Boyd, I. L., C. Lockyer, and H. D. Marsh. 1999. Reproduction in marine mammals. Pages 218-286 in J. E. Reynolds and J. R. Twiss, editors. Marine mammals. Smithsonian Institution Press, Washington, D.C., USA.

Breiwick, J. M., and E. D. Mitchell. 1983. Estimated populations size of the Bering Sea Stock of bowhead whales (Balaena mysticetus) from logbook and other catch data. Reports of the International Whaling Commission, Special Issue 30:147-151.

Chilvers, B. L., S. Delean, N. J. Gales, D. K. Holly, I. R. Lawler, H. Marsh, and A. R. Preen. 2004. Diving behavior of dugongs, Dugong dugon. Journal of Experimental Marine Biology and Ecology 304:203-224.

CIESIN [Center for International Earth Science Information Network] Columbia University, International Food Policy Research Institute, and World Resources Institute. 2000 Gridded population of the world (GPW), version 2. Earth Institute at Columbia University, Palisades, New York, USA. 〈http://www.ciesin.columbia.edu .

Coles, R. G., W. J. Lee-Long, L. J. McKenzie, and C. A. Roder. 2002. Seagrass and marine resources in the Dugong Protection Areas of Upstart Bay, Newry Region, Sand Bay, Lllewellyn Bay, Ince Bay and the Clairview Region, April/ May and October 1999. GBRMPA Research Publication 72. Great Barrier Reef Marine Park Authority, Townsville, Queensland, Australia.

Coles, R., L. McKenzie, and S. Campbell. 2003. The seagrasses of eastern Australia. Pages 131-147 in E. P. Green and F. T. Short, editors. World atlas of seagrasses. Present status and future conservation. UNEP World Conservation Monitoring Centre. University of California Press, Berkeley, California, USA.

Dayton, P. K., M. Tegner, P. B. Edwards, and K. L. Riser 1998. Sliding baselines, ghosts, and reduced expectation in kelp forest communities. Ecological Applications 8:309322.

Eberhardt, L. L., and T. J. O'Shea. 1995. Integration of manatee life-history data and population modeling. Pages 269 279 in T. J. O'Shea, B. B. Ackerman, and H. F. Percival, editors. Population biology of the Florida manatee (Trichechus manatus latirostris). National Biological Service, Information and Technology Report 1. U.S. Department of the Interior, National Biological Service, Washington, D.C., USA.

Gales, N., R. McCauley, J. Lanyon, and D. Holly. 2004 Change in the abundance of dugongs in Shark Bay, Ningaloo and Exmouth Gulf, Western Australia: evidence for large-scale migration. Wildlife Research 31:283-290.

GBRMPA [Great Barrier Reef Marine Park Authority]. 1981. Nomination of the Great Barrier Reef by the Commonwealth of Australia for inclusion on the World Heritage List. UNESCO. Great Barrier Reef Marine Park Authority, Townsville, Queensland, Australia.

Gerrodette, T. 1987. A power analysis for detecting trends. Ecology 68:1364-1372.

Gribble, N. A., G. McPherson, and B. Lane. 1998. Effect of the Queensland shark control program on non-target species: whale, dugong, turtle and dolphin: a review. Marine and Freshwater Research 49:645-651.

Haines, J., and C. J. Limpus. 2001. Marine wildlife stranding and mortality database annual report 2001. I. Dugong. Queensland National Parks and Wildlife Service, Brisbane, Queensland, Australia.

Haynes, D., J. Muller, and J. Carter. 2000a. Pesticide and herbicide residues in sediments and seagrasses from the Great Barrier Reef World Heritage Area and Queensland coast. Marine Pollution Bulletin 41:279-287.

Haynes, D., P. Ralph, J. Pranges, and B. Dennison. $2000 b$. The impact of the herbicide diuron on photosynthesis in three species of tropical seagrass. Marine Pollution Bulletin 41:288-293.

Heinsohn, G. E., and A. V. Spain. 1974. Effects of a tropical cyclone on littoral and sub-littoral communities and on a population of dugongs (Dugong dugon (Muller)). Biological Conservation 6:143-152.

Hilton-Taylor, C., compiler. 2000. The 2000 red list of threatened species. International Union for the Conservation of Nature and Natural Resources, Gland, Switzerland.

Jackson, J. B. C., et al. 2001. Historical overfishing and the recent collapse of coastal ecosystems. Science 293:629638.

Johnson, M. 2002. A modified form of whaling: the Moreton Bay dugong fishery 1846-1920. Pages 27-38 in Moreton Bay matters. Brisbane History Group Paper Number 19. Brisbane History Group, Brisbane, Queensland, Australia. Kwan, D. 2002. Towards a sustainable indigenous fishery for dugongs in Torres Strait: a contribution of empirical data and process. Dissertation. James Cook University, Townsville, Queensland, Australia.

Langtimm, C. A., T. J. O'Shea, R. Pradel, and C. A. Beck. 1998. Estimates of annual survival probabilities for adult Florida manatees (Trichechus manatus latirostris). Ecology 79:981-997.

Lanyon, J. M. 2003. Distribution and abundance of dugongs in Moreton Bay, Queensland, Australia. Wildlife Research 30:389-396.

Marsh, H. 1980. Age determination of the dugong (Dugong dugon) in Northern Australia and its biological implications. Reports of the International Whaling Commission (Special Issue) 3:181-201.

Marsh, H. 1995. Limits of detectable change. Pages 122-130 in G. Grigg, P. Hale, and D. Lunney, editors. Conservation through sustainable use of wildlife. Surrey Beatty and Sons, Sydney, New South Wales, Australia.

Marsh, H. 1996. Progress towards the sustainable use of dugongs by indigenous peoples in Queensland. Pages 139151 in T. M. Bomford and J. Caughley, editors. The sustainable use of wildlife by Aboriginal and Torres Strait 
Islander people. AGPS, Canberra, Australian Capital Territory, Australia.

Marsh, H. 2000. Evaluating management initiatives aimed at reducing the mortality of dugongs in gill and mesh nets in the Great Barrier Reef World Heritage Area. Marine Mammal Science 16:684-694.

Marsh, H., P. W. Channells, G. Heinsohn, and J. Morrissey. 1982. Analysis of stomach contents of dugongs from Queensland, Australia. Australian Wildlife Research 9:5567.

Marsh, H., P. Corkeron, I. R. Lawler, J. M. Lanyon, and A. R. Preen. 1996. The status of the dugong in the Southern Great Barrier Reef Marine Park. Great Barrier Reef Marine Park Authority Research Publication 41. Great Barrier Reef Marine Park Authority, Townsville, Queensland, Australia.

Marsh, H., G. De'ath, N. Gribble, and B. Lane. 2001. Shark control records hindcast serious decline in dugong numbers off the urban coast of Queensland. GBRMPA Research Publication 70. Great Barrier Reef Marine Park Authority, Townsville, Queensland, Australia.

Marsh, H. K., C. Eros, P. Corkeron, and B. Breen. 1999. A conservation strategy for dugongs: implications of Australian research. Marine and Freshwater Research 50:979990.

Marsh, H., and I. R. Lawler. 2001. Dugong distribution and abundance in the Southern Great Barrier Reef Marine Park and Hervey Bay: results of an aerial survey in OctoberDecember 1999. GBRMPA Research Publication 70. Great Barrier Reef Marine Park Authority, Townsville, Queensland, Australia.

Marsh, H., and I. Lawler. 2002. Dugong distribution and abundance in the Northern Great Barrier Reef Marine Park: November 2000. GBRMPA Research Publication 77. Great Barrier Reef Marine Park Authority, Townsville, Queensland, Australia.

Marsh, H., I. Lawler, D. Kwan, S. Delean, K. Pollock, and M. Alldredge. 2004. Aerial surveys and the potential biological removal technique indicate that the Torres Strait dugong fishery is unsustainable. Animal Conservation 7: $1-9$.

Marsh, H., H. Penrose, C. Eros, and J. Hugues. 2002. The dugong (Dugong dugon) status reports and action plans for countries and territories in its range. United Nations Environment Programme, Early Warning and Assessment Report Series, 1. United Nations Environment Programme, Nairobi, Kenya.

Marsh, H., and G. B. Rathbun. 1990. Development and application of conventional and satellite radio-tracking techniques for studying dugong movements and habitat usage. Australian Wildlife Research 17:83-100.

Marsh, H., and W. K. Saalfeld. 1989. The distribution and abundance of dugongs in the northern Great Barrier Reef Marine Park. Wildlife Research 16:429-440.

Marsh, H., and W. K. Saalfeld. 1990. The distribution and abundance of dugongs in the Great Barrier Reef Marine Park, south of Cape Bedford. Australian Wildlife Research 17:511-524.

Marsh, H., and D. F. Sinclair. 1989. Correcting for visibility bias in strip transect aerial surveys of aquatic fauna. Journal of Wildlife Management 53:1017-1024.

Mellors, J. E. 2004. Sediment and nutrient dynamics in coastal intertidal seagrass of north eastern tropical Australia. Dissertation. James Cook University, Townsville, Queensland, Australia.

Mitchell, E., and R. Reeves. 1983. Catch history, abundance, and present status of Northwest Atlantic humpback whales.
Reports of International Whaling Commission, Special Issue 5:153-209.

Myers, R. A., and B. Worm. 2003. Rapid worldwide depletion of predatory fish communities. Nature 423:280-283.

Nishiwaki, N., and H. Marsh. 1985. The dugong, Dugong dugon (Muller 1776). Pages 1-31 in S. H. Ridgeway and Sir R. Harrison, editors. Handbook of Marine Mammals. Volume 3. Academic Press, London, UK.

Oliver, J., and R. Berkelmans. 1999. A dugong research strategy for the Great Barrier Reef World Heritage Area and Hervey Bay. GBRMPA Research Publication 58. Great Barrier Reef Marine Park Authority, Townsville, Queensland, Australia.

Pandolfi, J. M., R. H. Bradbury, E. Sala, T. P. Hughes, K. A. Bjorndahl, R. G. Cooke, D. McArdle, L. McClenachan, M. J. H. Newman, G. Paredes, R. R. Warner, and J. B. C. Jackson. 2003. Global trajectories of the long-term decline of coral reef ecosystems. Science 301:955-958.

Poiner, I. R., and C. Peterken. 1996. Seagrasses. Pages 4045 in L. P. Zann and P. Kailola, editors. The state of the marine environment report for Australia. Technical Annex 1. Great Barrier Reef Marine Park Authority, Townsville, Queensland, Australia.

Pollock, K., H. Marsh, I. R. Lawler, and M. W. Alldredge. In press. Estimating animal abundance in heterogeneous environments: an application to aerial surveys for dugongs. Journal of Wildlife Management.

Preen, A. R. 1992. Interactions between dugongs and seagrasses in a subtropical environment. Dissertation. James Cook University, Townsville, Queensland, Australia.

Preen, A. R. 1995. Impacts of dugong foraging on seagrass habitats: observational and experimental evidence for cultivation grazing. Marine Ecology Progress Series 124:201213.

Preen, A. R., W. J. Lee Long, and R. G. Coles. 1995. Flood and cyclone related loss, and partial recovery, of more than $1000 \mathrm{~km}^{2}$ of seagrass in Hervey Bay, Queensland, Australia. Aquatic Botany 52:3-17.

Preen, A., and H. Marsh. 1995. Response of dugongs to largescale loss of seagrass from Hervey Bay, Queensland, Australia. Wildlife Research 22:507-519.

Reeves, R. R., J. M. Breiwick, and E. D. Mitchell. 1999. History of whaling and estimated kill of right whales, $B a$ laena glacialis, in the northeastern United States, 16201924. Marine Fisheries Review 61:1-36.

Roman, J., and S. H. Palumbi. 2003. Whales before whaling in the north Atlantic. Science 301:508-510.

Schaffelke, B., J. Waterhouse, and C. Christies. 2001. A review of water quality issues influencing habitat quality in dugong protection areas. Great Barrier Reef Marine Park Authority Research Publication 66. Great Barrier Reef Marine Park Authority, Townsville, Queensland, Australia.

Sergeant, D. 1977. Stocks of fin whales Baleonoptera physalus L. in the North Atlantic Ocean. Reports of the International Whaling Commission 27:460-473.

Thorne, E. 1876. The queen of the colonies. Samson, Low, Marson, Serle and Rivington, London, UK.

Wade, P. R. 1998. Calculating limits to the allowable humancaused mortality of Cetaceans and Pinnipeds. Marine Mammal Science 14:1-37.

Walters, C. 1997. Challenges in adaptive management of riparian and coastal ecosystems. Conservation Ecology 1(2): 1. 〈http://www.consecol.org/vol1/iss2/art1 .

Welsby, T. 1905. Schnappering and fishing in the Brisbane River and Moreton Bay waters. Outridge, Brisbane, Queensland, Australia. 